\title{
PRÁTICAS ALTERNATIVAS NO CAMPO DA ATENÇÃO AOS USUÁRIOS DE ÁLCOOL E OUTRAS DROGAS
}

\author{
Alba Riva Brito de Almeida Doutora em Saúde Pública (ISC/UFBA Professora \\ adjunta da Escola Bahiana de Medicina e Saúde Pública. \\ Psicanalista e da UNEB - Universidade Estadual da \\ Bahia
}

\begin{abstract}
Resumo
Este estudo enfoca uma experiência de intervenção junto a usuários de drogas numa instituição de referência. Pretende discutir questões relacionadas às práticas de atenção e cuidado a usuários de drogas e identificar a marca da construção da identidade institucional. A metodologia privilegia a entrevista, análise documental e estudo de caso com abordagem teórica de autores pós-estruturalistas. Identifica-se que a pluralidade de estratégias e de arranjos interdisciplinares utilizados pela instituição funcionam como meios alternativos para ressignificação da droga e revelam as ações face aos modos de assujeitamento dos usuários às práticas com drogas, bem como as leituras interpretativas acerca dos determinantes psicossociais da adesão.
\end{abstract}

Palavras-chaves: Práticas institucionais; Drogadição; Identidades; Sentidos e significações.

\section{ALTERNATIVE PRACTICES IN THE FIELD OF CARE TO USERS OF ALCOHOL AND OTHER DRUGS}

\begin{abstract}
This study focuses on the experience of intervention with drug users at an institution of reference. Discusses issues related to the practice of attention and care to drug users and identifies the brand of construction of institutional identity. The methodology focuses on interviews, documentary analysis and case study approach of with theoretical poststructuralist authors. We find that the plurality of strategies and interdisciplinary arrangements used by the institution to function as alternative means reframe the drug and reveal the actions against the modes of subjection to practices with drug of users, as well as interpretive readings about the psychosocial determinants of adherence.
\end{abstract}

Keywords: Institutional practices; Drug addiction; Identities; Meanings and significances.

\section{INTRODUÇÃO}

Este estudo analisa uma estratégia de intervenção junto a usuários de drogas e seus familiares, num Centro de referência em Salvador-Bahia, como um espaço de experimentação de práticas em saúde. Utilizou-se, como metodologia, a entrevista com os técnicos e coordenadores dos núcleos institucionais e a análise documental.

Baseia-se na especificidade das demandas das populações de usuários abusivos de drogas, a partir de que vem revendo suas atuações e adequando as suas estratégias, as quais não cessam de emergir do seio das próprias estratégias em voga e das que surgem a partir das iniciativas dos 
técnicos. Nesse sentido, verifica-se que a pluralidade de estratégias e de arranjos interdisciplinares utilizados pela instituição funcionam como meios alternativos para ressignificação da droga e revelam as ações face aos modos de assujeitamento dos usuários às práticas com drogas, bem como as leituras interpretativas acerca dos determinantes psicossociais da adesão.

A crescente preocupação com o aumento do consumo de substâncias psicoativas entre pessoas de diferentes camadas sociais, das mais diversas faixas etárias, assim como o incremento à geração de novas substâncias decorrentes da oferta do mercado vetoriza o interesse dos profissionais para a necessidade de revisão constante de práticas de intervenção nessa área.

Nesse sentido, a construção das práticas inscritas nesse espaço de trabalho em saúde foi orientada pela constatação do exercício contínuo de atitude crítica e reflexiva dos profissionais da clínica sobre os eixos constitutivos de suas intervenções nas perspectivas de atenção e cuidados praticados pela instituição. Essas perspectivas fazem emergir a vertente da operacionalidade associada à teoria da clínica. Indica, também, a polivalência de identidade epistemológica, o que contribui no exercício da interdisciplinaridade institucional.

A experiência institucional apontou para a necessidade da estruturação de ações integradas que permitissem oferecer mudanças mais efetivas na relação dos pacientes com as drogas, como também oferecer novas possibilidades de inclusão no contexto social e cultural em que estão inseridos. (fala de um coordenador)

As consequências diretas e indiretas do uso abusivo de substâncias psicoativas são percebidas não apenas no contexto da rede pública de saúde, mas principalmente nas interfaces da vida social: na família, no trabalho, no aumento de criminalidade, na disseminação do vírus HIV entre usuários de drogas injetáveis. Com o advento do crack, em 1998, houve um aumento significativo de demanda de tratamento no Centro, passando a ser incluídas, nos seus estudos, as categorias de exclusão e marginalização. Por essa razão, tornou-se imperativo a ampliação do quadro técnico e o implemento de novas estratégias clínicas, visando à otimização dos serviços prestados. As outras substâncias apontadas pelos participantes são a maconha (mais citada), seguidas pelo álcool e pelo tabaco, drogas consideradas lícitas. Embora essas drogas lícitas apareçam em grande proporção, as mesmas, geralmente, não motivam a busca de atendimento no Centro, sendo referidas em associação às substâncias ilícitas ou, então, apontadas como as 
primeiras substâncias experimentadas pelo paciente ao longo da vida. A grande maioria dos participantes é de poliusuários, que se referem à utilização de várias substâncias ao mesmo tempo, sejam elas lícitas ou ilícitas.

A possibilidade de construção de um entendimento técnico-teórico acerca do mapeamento do social que se delineia e materializa na instituição, associado aos impasses ou obstáculos operacionais das terapêuticas, parece ser um dos maiores desafios para os profissionais envolvidos nessas práticas:

Cada vez mais me convenço de que devemos conhecer mais sobre os espaços sociais dos jovens que acompanhamos aqui e que se nada acontecer, se não ocorrer alterações de base, nestes locais de origem, ficará difícil operar, tão somente, com os dispositivos clínicos. (fala de um coordenador)

A criação de um espaço de convivência, na instituição visou à criação de um lugar de permanência, propiciando ao usuário de drogas um atendimento adicional e alternativo que lhe possibilite realizar, de forma mais eficiente, a entrada e/ou continuidade do tratamento. É um lugar não circunscrito numa geografia, mas na dinâmica de atividades de acolhimento aos usuários de drogas.

A experiência institucional aponta para a necessidade de estruturação destas ações integradas que permitam o engajamento dos próprios adolescentes e jovens adultos usuários de SPA nos trabalhos realizados nas oficinas, o qual tem motivado os pacientes na construção de novos laços sociais, até então apagados pelos efeitos da substância utilizada e muitas vezes pelo envolvimento em atos delituosos que retroalimentam esse consumo. A grande parte desses pacientes não tem qualquer vínculo institucional e encontram-se brutalmente identificados como "viciados", "marginais", em situação de exclusão e consequentemente expostos a distintos riscos à sua saúde física e mental.

Os objetivos específicos das estratégias de intervenção, objeto deste estudo, são:

a) Acolher pacientes cujo perfil demande um programa de atenção e cuidados mais intensivos.

b) Promover atividades que reafirmem os laços sociais do paciente e seu reconhecimento social através da produção artístico-cultural. 
c) Estimular a escolha particular da(s) oficina(s), facilitando o deslocamento do objeto droga.

d) Ocupar, de forma criativa, o tempo de espera do paciente, entendendo-se essa espera como etapa da instalação da transferência à instituição e/ou ao terapeuta, vínculos estes essenciais na clínica psicanalítica.

e) Propiciar ao paciente um suporte adicional ao tratamento individual e/ou grupal.

f) Incentivar a produção artística como um novo instrumento de escolha que possibilite o deslocamento do objeto droga.

g) Ampliar as possibilidades de inserção sócio-cultural de adolescentes e adultos jovens usuários de drogas através de projetos de expressão e criação.

h) Oferecer recursos para que os participantes identifiquem novos interesses e talentos.

i) Assegurar uma atenção mais contínua em situação de abstinência ao uso de substâncias psicoativas.

j) Criar um espaço permanente de informação e prevenção de riscos e danos para os usuários de drogas.

A idade média dos participantes encaminhados para as atividades está entre 16 e 25 anos.

A grande maioria dos participantes nunca realizou qualquer tratamento anteriormente. Isso denota a dificuldade de muitos dependentes buscar ajuda quando necessário, bem como aponta para a importância desse primeiro contato institucional com o dependente de drogas. Essa importância se dá pela necessidade do estabelecimento de vínculos significativos nesse primeiro contato, uma vez que essa população é muito susceptível a rupturas, com dificuldades de retorno ao acompanhamento.(fala de um coordenador)

O estabelecimento dessas estratégias de intervenção têm o intuito de situar as questões levantadas pelo consumo de substâncias psicoativas pelos adolescentes e ampliar as possibilidades de respostas dadas pela instituição e a capacidade de atendimento aos jovens que demandam ajuda.

A necessidade de novos dispositivos para a criação de um espaço diferenciado de circulação de significantes a partir do tema "consumo de substâncias psicoativas" incentivou a busca de elementos teóricos que fundamentassem o fenômeno da 
adolescência, da maneira como é posto pelo discurso contemporâneo e pensado pela psicanálise. (fala de um técnico)

Fica evidente que as estratégias surgem como resposta à significativa demanda de adolescentes que buscavam atendimento no Centro e à constatada especificidade de tal população, no que diz respeito às formas de encaminhamento, no estabelecimento do vínculo institucional, na formulação da demanda de tratamento. São relevantes as diversas implicações do sujeito adolescente com o objeto droga, na singularidade do caso a caso, no nível de aderência tanto à instituição quanto ao acompanhamento ambulatorial propostos, além da consideração sobre os diferentes contextos familiares e sociais nos quais se inserem.

O percurso institucional até então com esses adolescentes permitiu-nos constatar, muitas vezes, que, no pano de fundo desse consumo, estão questões suscitadas por um mal-estar individual e familiar, além de outras relativas à sua inserção no meio social e cultural, enquanto sujeitos e cidadãos, particularmente nessa fase da vida. Tais aspectos apontam para a necessidade de estratégias específicas no tratamento do problema. (fala de uma técnica)

Muitas abordagens destinadas a lidar com os adolescentes privilegiam o caráter desorganizador do que é referido como "crise da adolescência, apropriando-se de um discurso normatizador, medicando e homogeneizando aquilo que o sujeito tem de particular, a sua subjetividade. (fala de uma técnica)

No âmbito do tratamento com adolescentes, particularmente aqueles que escolhem o uso abusivo de drogas e por vezes aos atos delinqüentes como a única saída possível, a aposta é que se possa produzir nesses sujeitos fatos de linguagem. Recuperar o valor da palavra apagada pelo ato. Não se trata aqui de lutar contra os atos, mas acreditar no poder simbólico da palavra. (fala de uma terapeuta)

O terapeuta operando no contexto institucional é convocado para a árdua tarefa de se fazer agente de uma possível inscrição, para que os atos se insiram numa cadeia de significações possíveis. Isso nos tem levado a refletir, nesse trabalho institucional, sobre as estratégias terapêuticas que possam, de alguma forma, dar conta dessa clínica. (fala de um terapeuta)

Esse projeto com adolescentes articula, também, o trabalho informativo e preventivo relativo ao consumo de substâncias psicoativas e suas interrelações com doenças sexualmente transmissíveis, particularmente a AIDS.

Os levantamentos estatísticos dos atendimentos realizados nos últimos anos pelo Centro registram uma significativa proporção de adolescentes na faixa etária de 16 a 18 anos, entre os 
pacientes implicados no consumo de substâncias psicoativas, com dificuldade de adesão ao tratamento psicoterápico individual e, muitas vezes, demonstrando rechaço ao trabalho, inclusive de permanência na instituição.

Uma avaliação preliminar revela a ausência de qualquer demanda, por parte do adolescente, o qual, pressionado pelos discursos mais contraditórios de seu meio familiar e social, atribui sua dificuldade momentânea à reação alarmista frente a um consumo de drogas que eles mesmos qualificam como não-problemático e que, de fato, passa ao largo da toxicomania.A ausência de demanda torna-os relativamente inacessíveis às formas usuais de atendimento disponíveis a instituição, embora o desconforto de sua posição sugira a necessidade de algum tipo de intervenção...(entrevista com uma terapeuta)

A experiência com adolescentes usuários de drogas vem demonstrando que o consumo de drogas faz referência ao próprio contexto da adolescência, sendo uma de suas modernas expressões. Este fato não chega a colocar esses adolescentes inteiramente ao abrigo dos riscos dessa prática, marcada por um reduzido apelo simbólico, sobretudo quando a maior parte da potencialidade e exuberância adolescente tende a nela se esgotar.

O grupo, por seus efeitos identificatórios, se justifica nesse contexto, não só por favorecer a formação do vínculo necessário ao desenvolvimento do trabalho, como por proteger a frágil unidade interna do adolescente, dos efeitos de uma diferenciação excessiva e/ou prematura.

Surge, então a alternativa de um espaço livre de discursos pré-estabelecidos, seja ele familiar, médico, psicológico, social ou legal, no qual a droga é, antes, tomada como algo próprio daquele sujeito que é convocado a falar dela, introduzindo a palavra, entre ele e a sua experiência química, com seus efeitos de re-significação. Na trilha aberta pelo tema da droga questões como sexualidade, morte, futuro, família, lei, vêm enriquecer o painel dos conflitos inerentes a esse período da vida, num trabalho que aponta para uma apropriação pelo adolescente, de sua própria adolescência.

Verifica-se, na proposição dos temas dos fóruns de discussão, assim como nas oficinas do espaço de convivência (estas mais ligadas ao fazer operativo), a repetição de situações concernentes ao mal-estar existencial do adolescente, no que tange às mutações do seu corpo e às insígnias imaginárias ou simbólicas que pode vir a portar, fenômenos estes que os anabolizantes tendem a neutralizar ou realçar; as situações de preconceito social e violência urbana, cuja incidência sobre os adolescentes aparece como pano de fundo das histórias de cada um deles; as 
dificuldades de inserção escolar, que convergem para a impossibilidade com que muitos lidam na construção de laços sociais garantidores de uma pertença possível e, por conseguinte, de uma identidade; os paradoxos do reconhecimento da lei e as vicissitudes que o exercício da transgressão comporta, como na aproximação ao tráfico de drogas e outras infrações juvenis; as questões ligadas ao risco à saúde e ao risco de morte e outros impasses com que os jovens se deparam nas questões sociais da contemporaneidade; a interveniência da mídia e dos outros recursos da tecnologia; a evidência das problemáticas familiares e outras dificuldades decorrentes da inexistência de políticas públicas coerentes e afinadas com as necessidades dos jovens como sujeitos e cidadãos, o que se afigura como saída crítica.

O intercâmbio com a comunidade, na forma da participação de palestrantes oriundos da academia, das instituições parceiras e outros profissionais ligados à assistência aos jovens usuários de drogas culminou por construir um grande painel de sentidos e significações, exibidos pelas diversas racionalidades através dos enunciados inscritos ao longo de cada apresentação.

A circulação da palavra que oscila entre o saber formal e o saber próprio de cada participante, como autores das cenas enunciativas teve, nesses fóruns, seu ponto de ancoragem, visto que os participantes são convidados a falar, nesta convergência de interesses e atividades comuns, no âmbito do tratamento e das ações educativas e preventivas, no campo da drogadição. Sujeitos retomados em seu discurso sobre o olhar, elaborar e saber-fazer na dimensão de engenho instituinte, metáforas do que o Centro incorpora através da produção de trabalho interinstitucional concreto; confluência de discursos que visam a acompanhar a magnitude dos movimentos das singularidades dos jovens nas formações sociais que funcionam como causa e dobradiça das reconstruções anunciadas pelos temas.

Os discursos veiculados na instituição culminam por legitimar as possibilidades de multiplicar as "Expressões criativas nos tratamentos com usuários de drogas" e de leituras sobre "O sujeito e a droga, entre o passado e o futuro", trazendo, nas suas articulações, "Propostas de vida para os jovens”. De todos os modos, perspectivas que só serão válidas se reconhecidas nas "Palavras de adolescentes". 


\section{OS ARTÍFICES DA ARGILA INSTITUCIONAL}

A experiência clínica institucional com usuários de substâncias psicoativas e seus familiares suscitam entre os técnicos que lidam com essa população uma série de questões teóricas e práticas. As respostas são múltiplas entre os que tratam desse fenômeno, impondo a necessidade de se vislumbrar modelos estruturais novos, para dar conta da especificidade dessa manifestação e dos impasses que se anunciam na demanda de tratamento.

Observamos que muitos pacientes chegam ao Centro absolutamente tomados pelos efeitos mortificantes do produto, não havendo possibilidades para a instauração de um tratamento apenas a nível ambulatorial. Os cuidados clínicos imediatos e, muitas vezes, a opção do internamento revela-se como o último recurso possível para a manutenção da vida do paciente.

Verificamos, entretanto, que uma gama significativa de pacientes que buscam atendimento, além da escuta psicoterápica e do suporte psiquiátrico, sobretudo em períodos de abstinência do produto ou quando desejam afastar-se dos locais de utilização contínua do produto, se beneficiam com outras modalidades de tratamento.

As propostas, sustentada por diversas atividades nomeadas como Oficinas, constitui-se num espaço terceiro na relação dual que se estabelece entre o paciente e a substância psicoativa, favorecendo o deslocamento desse sujeito em relação ao produto de consumo.

O projeto desenvolvido através das oficinas mostrou-se inédito como uma estratégia de atenção aos usuários de drogas porque busca deslocar o foco dos processos de desintoxicação em clínicas ou instituições psiquiátricas e voltar-se para a inserção do usuário nos processos criativos e nas possibilidades de inclusão social, o que pode acontecer pela via da arte e das intervenções urbanas. Muitas estratégias enfatizam a droga apenas como "um mal a ser abolido", sem levar em consideração os contextos familiares, sociais e culturais em que se organiza esse consumo. (fala de um coordenador)

Ao longo do trabalho de pesquisa desenvolvido, pudemos verificar, nas entrevistas com os monitores de Oficina e coordenadores, a importância dessa modalidade de intervenção junto a esses pacientes.

Uma grande parte dessa população não tinha qualquer vínculo escolar ou de trabalho, colocando-se em situações de risco, tanto pela utilização da droga, como pelo envolvimento em atos delituosos. Os relatos dos participantes que se encontram em 
situação de ruptura social é de que, muitas vezes, o espaço do projeto era o "único lugar" que eles têm para ir, referindo-se, em muitos momentos, às oficinas como "cursos" onde "aprendem" algo e "são escutados. (fala de um coordenador)

A música, o teatro, o grafite, a fotografia, a inserção digital ofereceram recursos que propiciaram, em muitos momentos, o afloramento da dimensão subjetiva de cada um, criando possibilidades de escolha, comprometidas, até então, pelos efeitos encobridores da substância utilizada:

A importância dessa modalidade de intervenção junto à população de usuários de substâncias psicoativas acontece, prioritariamente, pela oferta de recursos que promovem, em muitos casos, o surgimento da dimensão subjetiva de cada um, apresentando-lhes possibilidades de escolha, que, até aquele momento, estava amarrada apenas pelo uso das substâncias psicoativas. Com as oficinas, algumas pessoas retomam questões de suas vidas, até então esquecidas por esse consumo excessivo, como a dimensão do tempo, do espaço, do cuidado corporal. (fala de um coordenador)

$\mathrm{Na}$ avaliação realizada pelos coordenadores das oficinas, podemos observar a repercussão desse trabalho nos participantes envolvidos, bem como verificamos que algumas atividades puderam se organizar em consonância ou a partir do trabalho efetuado. Listamos alguns desses dados: interesse demonstrado pelos participantes de se engajarem em projetos em áreas ou temas correlatos ao trabalho desenvolvido nas oficinas; participação dos integrantes do projeto em eventos realizados pelo Centro com outras instituições, articulando os trabalhos realizados pelas oficinas; engajamento dos participantes nos encontros mensais do Fórum Interinstitucional sobre Adolescência e Drogas com discussão de temas relativos à lei, à sexualidade, ao trabalho, ao exercício da cidadania, dentre outros; capacitação de agentes de Intervenção Urbana na prevenção do Abuso de Drogas e DST/Aids; mudança de comportamentos em relação às práticas de consumo de drogas, conforme relatos dos participantes nos acompanhamentos e nas avaliações realizadas; criação de novos vínculos sociais e afetivos, conforme relatos dos participantes nos acompanhamentos e nas avaliações realizadas.

Também, segundo relato dos coordenadores, monitores e participantes envolvidos, pudemos constatar que o trabalho nas oficinas permitiu a discussão constante do respeito ao outro, na perspectiva da construção coletiva, bem como da incidência das diversas dimensões da lei, buscando resgatar formas de socialização que, na maioria das vezes, vinham se organizando para esse pacientes em torno da aquisição e utilização dos seus produtos de consumo: 
Trabalhar com uma população dessa natureza, tomada muitas vezes pelos efeitos de dependência da droga, impõe dificuldades no processo de trabalho. Por isso, estamos fazendo discussões sobre o respeito ao outro, sobre como se sentem afetados, ou não, pelas diversas cobranças da lei, para tentar reestruturara a socialização que, na maioria das vezes, se organiza somente em torno da droga. (fala de um coordenador)

O relato dos pacientes e dos monitores de Oficina aponta para uma relação estreita entre um maior engajamento no trabalho das oficinas e a diminuição da freqüência de uso do produto, ou mesmo, da suspensão da substância que motivou sua vinda ao Centro, ainda que mantivesse o uso de substâncias de menor dano, ou que, eventualmente, pudessem usar uma maior quantidade de droga em momentos de crise.

Diante do grande número de pacientes que buscam a instituição, percebemos que o recurso das oficinas ainda pode ser mais amplamente utilizado pelos técnicos envolvidos no Núcleo de Clínica, como parte dos projetos terapêuticos de pacientes atendidos ambulatorialmente. Por outro lado, percebemos também que muitos pacientes encaminhados não chegam a freqüentar as oficinas, o que requer uma maior discussão sobre as formas de encaminhamento e as expectativas desses técnicos em relação ao trabalho desenvolvido no projeto.

Acreditamos que a atenção ao usuário de substâncias psicoativas deve ser buscaada, para além dos cuidados médicos e de acompanhamento psicoterápico. Por isso, são promovidas oportunidades de inserção social desses grupos estigmatizados e marginalizados, que estão excluídos muitas vezes não só pelo consumo das substâncias psicoativas, mas também pelas precárias condições sócio-econômicas a que estão submetidos e que comprometem o exercício dos seus direitos e deveres básicos de cidadão. (fala de um coordenador)

A captação desses dados, que reverberam desde a estrutura da ordem social, é feita através do discurso, como um dos eventos da linguagem. Para Ricoeur, (1, p. 20) "um ato de discurso não é simplesmente transitório e evanescente"; preserva uma identidade própria, a qual se aloja na estrutura de linguagem, articulada a outras redes de significações. A natureza complexa da linguagem aqui se faz representar, visto que a linguagem é o próprio fundamento e a explicitação da materialidade de uma causalidade estrutural. 
No caso das instituições públicas, pelos efeitos no cenário revelados pelos entraves e impasses quanto às referências epistemológicas, aos diversos sentidos e aos recortes metodológicos e olhares sobre a apreensão e definição de um sintoma social como a drogadição. Foucault já nos alertara que

[...] a clínica constitui uma das tentativas de ordenar uma ciência pelo exercício e decisões do olhar , [...] um olhar que escuta e um olhar que fala: a experiência clínica representa um momento de equilíbrio entre a palavra e o espetáculo. ${ }^{(2, \text { p.112) }}$

O olhar tomado pelo evento e como concepção prévia : olhar sobre o processo e sobre os sujeitos que operam segundo as diferentes perspectivas ou modelos. oferecendo alguns meios (as estratégias), para tornar possível essa operação. Esta necessidade de transparência do olhar pode ser também aludida quanto às contradições inerentes à problemática da exclusão ou segregação do campo das toxicomanias, no sistema de saúde do Estado, quando foi incluído na seara das doenças mentais.

Ao permitir uma convivência entre os participantes e o estreitamento de laços afetivos, as oficinas possibilitam um "olhar"do outro, do grupo, tornando-se uma referência importante da conduta de cada um,o que pode ajudá-los no processo de abandono das drogas. (fala de um coordenador)

As oficinas representam um lugar de aprendizado social e subjetivo.Alguns participantes afirmam que, nas oficinas, experienciam um processo de "descoberta" de seus próprios talentos, que surgem "naturalmente" quando realizam as atividades propostas. Exatamente por isso que alguns participantes dizem que se percebem e percebem aos outros de modo diferente. (fala de um coordenador)

O fator desencadeador de uma nova proposta ou o reconhecimento de alguma delas pode ser, e isso acontece de forma bastante recorrente, o índice de prodigalidade ou de visibilidade atribuídas aos mentores ou operadores daquela iniciativa, a partir das respostas obtidas dos participantes:

As oficinas representam um lugar de preenchimento do espaço e tempo ocioso, aspecto particularmente importante para o grupo, cuja ausência de atividades laborais, escolares e sociais favorece o uso de drogas. (fala de um técnico) 
Experienciar novas relações dentro da instituição possibilita, para alguns, uma melhoria no convívio com suas famílias e com outros atores sociais, como também com os professores com os quais se relacionam na instituição.(fala de um técnico)

O aprendizado nas oficinas aparece como um motivador da construção de um projeto futuro, para a vida profissional e para a vida pessoal. (fala de um técnico)

As oficinas são uma modalidade terapêutica que, conjugadas às terapias individuais e ao tratamento medicamentoso, auxiliam os participantes a restringir ou abandonar as drogas. É por isso que o cuidado oferecido pela instituição, a partir de terapia, medicamentos e oficinas é apontado como modelo mais eficaz no tratamento do abuso de drogas. (fala de um coordenador)

Geralmente, são os técnicos já pertencentes ao quadro do Centro que capitaneiam esses projetos e os põem em ação, quer dizer, alguém toma para ser feito algo que está aí "à mostra". Vale acrescentar que a iniciativa ganha importância quando há a convocação de reconhecimento do Outro social (a comunidade e as instituições parceiras) e do outro semelhante (os outros técnicos da instituição que não participam do projeto). Essa atitude produz efeitos positivos e soluciona problemas tangenciais:

Os participantes associam a realização das Mostras a um momento no qual podem apresentar o resultado de seu aprendizado individual, além de se constituir como um espaço fundamental de reconhecimento social pelo trabalho realizado. Por isso, a Mostra se liga à elevação da auto-estima dos participantes, contribuindo para o engajamento dos usuários nas atividades institucionais. (fala de um coordenador)

Uma análise geral dos modelos instituintes das práticas do Centro sublinha o estilo subversivo dos mesmos, quanto aos pontos de vista político-ideológico circundantes ("combate" às drogas, vinculação das drogas ao crime, loucura, sexo, e morte, por exemplo) e às retóricas dogmáticas vigentes desde sempre (a falácia preventiva embutida nas advertências religiosas e nos intentos de uma pedagogia ortopédica do usuário dito "problemático").

Uma demonstração desta função enunciativa das práticas do Centro é explicitada nas atividades voltadas para a adolescência e o consumo de drogas sustentado, dentre outros, pelo discurso de combate a uma "teoria do desvio", a qual acentua a dimensão motivacional do desvio decorrente do comportamento desviante, este concebido numa perspectiva patologizante. 
O enfoque empregado nas atividades tem sido o funcional, quando procura delimitar como a estrutura social e cultural produz a pressão que propicia a construção e apresentação de comportamento socialmente desviado, sobre indivíduos situados de maneiras distintas naquela estrutura. Trata-se de compreender, na esteira de Becker, ${ }^{(3)}$ que "os grupos sociais criam o desvio ao estabelecer as regras cuja infração constitui desvio". Por este ponto de vista, o desvio não é a condição do ato que a pessoa faz, mas a conseqüência da aplicação por outrem de regras e sanções ao "transgressor". (3, p. 8-9)

O atravessamento dos conceitos de desvio e segregação, contribuição efetiva da antropologia no seio do Centro, foi afiançado pelo discurso psicanalítico, na leitura da singularidade da apropriação do mal-estar inerente aos jovens na contemporaneidade. Nesta direção, o "coração do problema"(4) seria o reflexo, na subjetividade de cada adolescente, dos lugares sociais que ocupam e das intensidades psíquicas que lhe sobredeterminam.

Como prática que visa à abordagem pluridimensional da adolescência e suas vicissitudes, margeadas pela relação com a droga, o Centro vem se dedicando a buscar a aproximação com outras instituições que também se dedicam a adolescentes, com o intento de aprimorar estratégias de intervenção para os problemas relatados pelos jovens. O que nos parece relevante destacar neste programa é a adequação do formato das atividades àquelas especificidades que integram o universo dos jovens, quais sejam, o incentivo à produção artística através das oficinas de expressão e criação.

Assim, as estratégias adotadas definem-se como um "lugar sem drogas, tendo por função acolher o paciente de forma intensiva, ocupando-o com atividades complementares elou suplementares ao acompanhamento psicoterápico ou psiquiátrico proposto pelo Centro" (relatório junho/2005 a maio/2006). Esta prática tem se mostrado como de grande importância na manutenção e sustentação do tratamento de alguns pacientes.

A expressão "lugar sem drogas" alude à concepção da instituição como um espaço dialógico, retirando o foco no produto e promovendo a construção contínua de laços sociais, mediante a apreensão de símbolos extraídos da experiência cotidiana (como exemplos, as oficinas de artes visuais e fotografia), como presenças gigantescas de representações simbólicas, de um universo de linguagem manifestamente reduzido na permanência da droga.

Se a linguagem é capaz de transcender a realidade cotidiana, ${ }^{(5)}$ pensamos ser possível constituir-se, como objetivo do Espaço de Convivência, uma ratificação das possibilidades de 
inserção sócio-cultural e de posição subjetiva, no resgate da temporalidade do sujeito e do engendramento de novos sentidos para o mundo que ele constrói e vivencia objetivamente, desprovida da mistificação da realidade da droga, dissecando as funções sociais da droga. O deslocamento da relação do paciente com a droga resignificará, como realidade tangível, as marcas de um exílio no campo das relações sociais mais amplas, principalmente no âmbito dos responsáveis pelo controle social: família, estado, escola, uma vez que sua compreensão da realidade encerra o atar e desatar pontual dos nós de linguagem, apresentados nos dialetos sedimentados pelos segmentos da realidade, definidos como comunidades de compartilhamento da droga.

Se os significados das drogas são diferentes (do ponto de vista psicológico, médico, ideológico, policial,), os efeitos serão diferentes para aqueles que estão sob condições sociais diferentes. Por conseguinte, os sujeitos drogaditos não podem ser contados pelas semelhanças:

As oficinas instituem, ainda que provisoriamente, uma nova identidade aos participantes, abordados e percebidos como "artistas" e não como "drogados". A presença dos amigos, da família, de estudantes universitários, de ONGs e outras instituições confirmam essa imagem positiva associada ao que, exposto nas Mostras. Ao mesmo tempo, ela institui este novo sentido aos participantes. (fala de um técnico)

A oposição à estereotipia dos discursos sobre a droga, além da consideração das concepções diferenciadas do uso, abuso e dependência formaram o ponto de partida decisivo para o alcance do projeto institucional do Centro, o qual se atualiza permanentemente nas práticas devido às aporias do seu funcionamento com os condicionamentos políticos internos e externos.

Não obstante as diferenças teóricas e metodológicas, o Centro pretende funcionar como um decifrador das estruturas subliminares ao consumo de drogas, mediante os saberes que se mostram qualificados para opinar sobre essa relação específica do sujeito com a droga. Embora pautado em controvérsias, essa sua posição dá suporte à condição de descontinuidade, ou seja, de manutenção do hiato no lugar da verdade absoluta e derradeira sobre os sentidos das toxicomanias. Isso ocorre porque a linguagem não se reduz à trama dos discursos, no formalismo dos seus enunciados, ou na tentação de converter-se, meramente, num paradigma panfletário de saberes especializados, esperando, com esta lógica, que a verdade da diferença se inscreva e se expresse: 
É importante se colocar em ação os operadores da linguagem, neste trabalho com usuários de drogas. Isso porque a estereotipia do seu discurso e sua fragilidade no exercício do simbólico exigem uma abertura, por parte dos profissionais que lidam com eles, de compreensão sobre a multiplicidade dos sentidos das drogas e do modo como cada um se encaixa neste universo de sentidos tão diversificados. (fala de um coordenador)

A consideração única das drogas como uma representação globalizada e homogeneizada do mundo contemporâneo culmina por apagar os traços de identidade e o reconhecimento da singularidade dos usuários de drogas. As concepções teóricas vigentes no Centro envolvem a noção de sujeito, a qual está intrinsecamente vinculada à perspectiva do ser humano como um projeto articulado às idiossincrasias de cada um. Como projeto sempre renovado, não fica subsumido por modelos prévios, porque se ancora na questão de que as drogas são instrumentalizadas para finalidades diversas: afetiva, subsistência, afirmação de identidade, negação, reconhecimento, pertença e outros.

Esperamos que estas oficinas ajudem na operação de separação com o objeto-droga e, também, que esse adolescente usuário apareça não como identificado ao nada que esta adicção promove, mas a uma nova condição de inserção no mundo, como sujeito responsável, que sabe articular uma vida própria. (fala de um técnico)

O sujeito drogadito é responsável pela produção que estabelece na montagem com o objeto-droga. As noções de responsabilidade e ética apontam para o desejo do sujeito, como elemento a ser construído e tornado permanente no discurso. O sentido do ser (como subjetividade) e o estar (como estrutura pré-existente) no mundo, se fundem na modelagem do uso metódico de uma substância psicoativa, o que reduz a tendência à dicotomia presente em algumas análises fenomenológicas ou pragmáticas.

\section{CONSIDERAÇÕES FINAIS}

O recuo diante dos movimentos de inteligibilidade ou de construção de modelos justapostos a uma única vigência de pensamento sobre a relação do sujeito com a droga permite o redimensionamento do fato, hoje denominado toxicomania, trazendo para o centro da cena, a singularidade de cada sujeito em sua relação com o objeto, estruturalmente grampeado pelos 
paradoxos sociais. Essa particularidade de relação encerra o mapeamento das razões mínimas de funcionamento da relação do sujeito com o mundo:

Um traço comum nos discursos que circulam nas oficinas é o apego ao produto que, sabemos, não é o problema. O produto é a coisa inerte; ele só vai exercer suas funções na medida em que alguém o toma e ele usa ou abusa, quer dizer, segundo os modos de uso. $O$ fato é que o objeto-droga significa a totalidade dos interesses desses jovens, não restando o espaço vazio que poderia ser ocupado com outros investimentos no mundo. (fala de um coordenador)

O que se constitui permanentemente nessas complexas dimensões racionais e tecnologias é a linha da identificação do objeto de demanda dos sujeitos que acorrem ao Centro. A concepção de um objeto total, ${ }^{1}$ cabível àquele que supostamente o apreendeu, parece ser o próprio fundamento da relação do sujeito com a droga, posto que é em torno dessa "coisa", inacessível em seu fundamento que ele se orienta. Faz-se mister advertir de que não é a droga como $o$ produto em si mesmo, mas a droga-coisa, algo que, no campo do humano, pode desembocar na impossível realização de uma satisfação e na igualmente, impossível, adequação perfeita do sujeito aos seus objetos.

A relação estrutural entre sujeito e objeto ultrapassa os limites da dualidade cartesiana, embora as ciências sociais tenham se esforçado, por muito tempo, para construir um saber fundado sob o empirismo da observação e da compreensão das relações de causa e efeito, ${ }^{(6)}$ se confrontando permanentemente com o dilema da objetividade das suas observações. Isso na inclusão da existência de um transitivismo de ordem imaginária, marcado pelas indeterminações e oscilações do sentido. Esta implicação estrutural indica que a relação com a droga está

\footnotetext{
${ }^{1}$ A noção de objeto a que nos referimos aqui diz respeito à distinção, no alemão, dos termos das Ding $e$ die Sache,que designam, ambos, "coisa". Contudo, o objeto não se confunde com a coisa, embora, por vezes, dê provas do papel que possa vir a desempenhar: "o objeto - uma vez que especifica as direções, os pontos de atrativo do homem em sua embocadura, em seu mundo, uma vez que o objeto lhe interessa por ser mais ou menos sua imagem, seu reflexo - esse objeto, precisamente, não é a Coisa" ${ }^{\left(8, p^{1.140-1}\right)}$ Acrescentamos que esta busca engendra a aporia entre das Ding e die Sache: procuramos das Ding (a coisa como vazia de representação) e encontramos die Sache, (a coisa, "o produto da indústria ou da ação humana enquanto governada pela linguagem, algo que nos vem à consciência se prestarmos bastante atenção a ela, se a notarmos", ${ }^{(8, \text { p.140-1) }}$ coisa acessível e explicitável pelas palavras; explicitação dos dramas (tragédias e comédias) humanos mais recônditos.
} 
determinada pelas modulações da relação sujeito-objeto, quanto ao gozo e quanto à irrupção do sentido através do sensível ${ }^{(7)}$ referido a um objeto que se lhe apresenta como semblante.

O característico do agir toxicomaníaco é tentar reenviar o sentido para o lado do significado, na medida em que descreve o objeto de sua satisfação como coisa acessível; o objeto toma uma materialidade, uma substância, dá-se a crença de que é possível gozar desde que dele se aproprie. O sujeito percebe o objeto (o sujeito faz a droga), dá-lhe sentidos, os quais possuem uma natureza sempre ficcional, posto que "não existem relações naturais entre o mundo e a

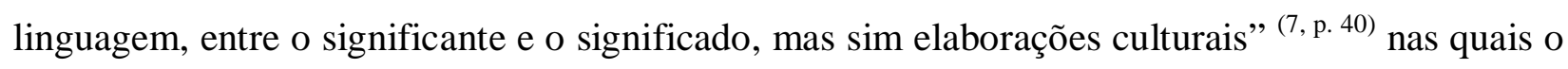
sujeito pode apagar-se, como na drogadição.

Portanto, a droga comparece no contexto institucional não como pura exterioridade, da qual se deveria livrar para iniciar-se um tratamento, mas como parte integrante do indivíduo. Disso resulta que a droga passou a desempenhar um papel central na organização desse sujeito, ocupando lacunas importantes da sua estrutura (esta que se imiscui no campo social), tornandose, assim, o próprio fundamento da sua subjetividade, ao contrário da regra durkheimiana, segundo a qual poderíamos deduzir o fato social da drogadição como uma "coisa".

Para Durkheim, ${ }^{(9)}$ o substrato material das representações coletivas não está atrelado às representações individuais nem à soma destas; as representações coletivas se atraem, repelem, ou formam sínteses que não estão exatamente atreladas a estruturas sociais, ou ao estado do meio onde evoluem. Elas se interpenetram, numa rede de linguagem, fundando realidades simbólicas que transcendem o mundo imediato. As representações coletivas, portanto, encerram "forças coletivas", simbolicamente ativas e constitutivas da sociedade como totalidade integrada, com caracteres e funcionamentos que denotam as leis das relações coletivas e os contrastes entre diferentes sociedades. Esta postulação de um determinismo exclusivo das leis sociais se contrapõe ao "valor que liga o sujeito aos seus objetos", (10, p. 108) este que opera a reversão do sentido positivista de apreensão da realidade, visto que coloca a relação do sujeito com o objeto aberta a várias leituras possíveis.

Conforme já sinalizamos, os significados sociais do uso de droga, naquilo que não pode ser compreendido como estando em função de determinadas causações, numa ideação fenomenológica da presença, tão somente ${ }^{2}$, serão sempre especificados pela dialética do sujeito

\footnotetext{
${ }^{2}$ Extraímos de Laplantine ${ }^{(7, \text { p.108) }}$ uma importante conclusão acerca da posição dos fenomenólogos e sua inscrição na tradição racionalista, a qual clama a "garantia da realidade, da estabilidade, da unidade, do caráter unívoco e da 
com o simbólico. Qual a relação interpretativa que mantenho com o Outro social, este que porta o imperativo GOZA!? Espera-se que a condição de submetimento a este imperativo venha se esboçar no horizonte de um tratamento, quando o sujeito perceber as modalidades de respostas denotadas pelo seu comportamento, pelas desmotivações para o estudo, trabalho ou sexo e "fissuras" pela droga:

Os pacientes, tanto os que perambulam pelas ruas, quanto os que chegam ao ambulatório, não trazem uma demanda de tratamento formalizada. Ele não tem uma leitura sobre o seu lugar social, nem tem noção do que perde. No máximo, ele pode falar da sua condição de excluído, de sofrer preconceitos, de não ter onde morar, porque a família não o quer, mas ele dificilmente se dá conta, espontaneamente, de que sua condição de vida é decorrente de a sua relação com o lucro estar invertida, porque o que ele faz é enriquecer o traficante. (fala de um coordenador)

Assim, as determinações do sujeito estão situadas sob a égide da estrutura que o suporta ou acopladas a um lugar específico no discurso dominante, o que muitas vezes aparece nas relações intersubjetivas de maneira cristalizada, estagnante e inerte, sinalizando os movimentos de interpretação dos profissionais acerca dessas posições do sujeito no mundo. Estas posições dizem respeito à crença de que os objetos podem ser integralmente consumidos, não constituindo nada a faltar.

A expressão "sujeito afetado pelos objetos", ${ }^{3}$ versão recitativa da hegemonia dos objetos sobre o sujeito apregoado pelo discurso do capitalista parece, enfim, sintetizar o modelo social de mercado atual, o qual tem uma função precípua na oferta dos chamados "gadgets" (objetos descartáveis) e estes possuem correlato com a ciência e seus avanços tecnológicos, o que culmina por determinar um tipo de organização da realidade social, esta que estamos neste estudo definindo como circunscrita ao imperativo GOZA!.

As perspectivas de tratamento com usuários de drogas, nessa instituição, partem do princípio de que os usuários partilham de uma realidade idêntica, na acepção de que estão

exterioridade de um sentido já existente, não havendo, nessas condições, necessidade de preocupar-se coma a linguagem que, com seu caráter equívoco, se apresenta como sendo um obstáculo ao conhecimento".

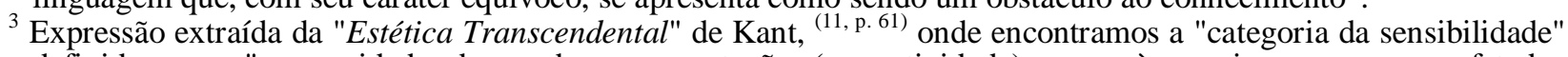
definida como "a capacidade de receber representações ( receptividade), graças à maneira como somos afetados pelos objetos". O sujeito, nesta Estética, é concebido como agente de associações de representações sensíveis, uma vez que a coisa em si não pode ser conhecida. A noção, por conseguinte, de "sujeito afetado pelos objetos" adquire seu fundamento no aspecto formal (espaço e tempo), fornecendo objetividade ao fenômeno, tornando-o objeto. Os objetos da experiência incidem sobre o sujeito na medida em que a consciência se constitui por estes objetos, podendo formar conceitos puros da razão. 
adequados a uma verdade de um discurso que os torna plasmados dentro de um sistema de assujeitamento social, ficando alijado na circulação do lucro, não participando da mais-valia.

O sujeito plasmado no objeto "ilustra não somente a renúncia à mais-valia e ao seu desconhecimento, mas, pelo menos no início, o seu descrédito". (12, p. 30) É importante considerar este aspecto da posição do usuário na configuração social, posto que o "mundo do sujeito e o do social constituem um único e mesmo universo", ${ }^{2}$, p. ${ }^{31)}$ este que penetra pela porta das salas de atendimento, trazendo dificuldades e angústias ao terapeuta: "O que angustia o terapeuta é reconhecer sua limitação diante de realidades tão díspares e tão misturadas”.

Para finalizar, lembramos que a "estrutura intersubjetiva da constituição de sentido pode ter muitos significados, conforme o código sócio-cultural", ${ }^{(13, \text { p. }}{ }^{80-81)}$ de acordo com a rede de prevalências e dos campos de força das significações que se pretende atribuir à concepção de objeto insubordinado encerra.

Em decorrência da natureza móbil dos enlaces institucionais e da função até então exercidas pelo estilo gerencial, alguns projetos culminam por atuar, também, como elemento de "amarração" da instituição, como nó de estrutura para os demais ordenamentos e desenhos funcionais dos núcleos.

A exigência de trabalho imposta aos profissionais se ancora no manejo da vacilação e insubordinação do seu foco de trabalho (o sujeito usuário e suas relações com o objeto eleito), mesmo diante da implementação incessante do exercício de contornos e decifrações (a multivocalidade institucional) nessas relações.

A impossibilidade de barrar e esvaziar o objeto-droga responde pelas situações em que são permanentemente salientadas as repetições ou "recaídas" dos pacientes, impulsionando o eterno retorno à questão dos resultados ou da eficácia dos métodos utilizados pela instituição. Essa questão está, intrinsecamente, grampeada à noção de abstinência (geralmente associada à de eficácia do tratamento). Esta condição encontra seu limite no inacessível desta plenitude, sempre de natureza pontual, visto que é na tensão entre submissão e emancipação, racionalização e subjetivação $^{(14)}$ que o sujeito se implica na história e na produção ou reconhecimento da dimensão ética que lhe concerne. 


\section{REFERÊNCIAS}

1. Ricoeur P. Teoria da interpretação: discurso e o excesso de significado. Lisboa: Edições 70; 1976. Capítulo 1. Linguagem como discurso, p. 20.

2. Foucault M.O nascimento da clínica. Rio de Janeiro: Forense Universitária; 1998. p.112.

3. Becker H. Outsiders. New York: The Free press; 1973.

4. Bibeau G, Perreault M. Comprendre la 'marge' pour agir au coeur du problème. Montreal : Boréal; 1995.

5. Berger PL, Luckmann T. A Construção social da realidade. Petrópolis: Vozes; 1966. Capítulo 1. Os fundamentos do conhecimento na vida cotidiana; p. 31-45.

6. Ghasarian C. Sur les chemins de l'ethnographie réflexive. In: Ghasarian C., directeur. De l'ethnographie à l'anthropologie réflexive. Paris: Armand Colin; 2004. p. 34-35.

7. Laplantine F. La description ethnographique. Paris: Armand Colin; 2005.

8. Lacan J. O Seminário. Livro 7, A ética da psicanálise (1959-1960). Rio de Janeiro, Jorge Zahar; 1991.

9. Durkheim E. As regras do método sociológico. Lisboa: Presença, ano. Capitulo XX. O que é fato social; p.89.

10. Gaboriau P. Point de vue sur le point de vue: les enjeux sociaux du discours ethnologique: l'example des sans logis. In: Ghasarian C., directeur. De l'ethnographie à l'anthropologie réflexive. Paris: Armand Colin; 2004. p. 23.

11. Kant I. Crítica da Razão Pura. Tradução: Manuela Pinto dos Santos e Alexandre Frandique Morujão. Lisboa-Portugal: Fundação Calouste Gulbenkian; 1985. p.61.

12. Chemama R. Um sujeito para o objeto. In: Goldemberg R., organizador. Goza!: capitalismo, globalização, psicanálise. Salvador: Ágalma; 1997. p. 23-39.

13. Izer W.O ato da leitura: uma teoria do efeito estético. São Paulo: Editora 34; 1999. Volume 2.

14. Touraine A. Crítica da modernidade. Petrópolis: Vozes; 1994.

Revista Psicologia, Diversidade e Saúde, Salvador, dez. 2012; 1(1): 109-128. 